size of which would save it from many blows which a big, soft, vascular female breast must encounter. Moreover, it is contended that if blows caused mammary cancer the lesions would be multiple, but this just shows how things appear differently to different people, for I do not suppose that if a woman gets an injury to her breast she gets it in the form of a series of thumps all round so as to produce multiple cancers. I have received very succinct accounts from intelligent women of blows from pieces of furniture or kicks from young children in which there was pain immediately afterwards sufficiently severe to fix the exact place in the breast in the memory. Then the pain has gone away and they have almost forgotten the circumstance until some day a lump is found at the old site of injury. Were the allegation true that the injury directs the woman's attention to a tumour which is lying concealed in her breast already, then she would discover it at once on receipt of the injury, but this is not the history of these cases. The history is that of an interval after which the lump comes painlessly. Many of the patients whose histories I have ascertained were far too intelligent to have invented the story after finding the lump. Mr. Roger Williams says that in examining the cases of 137 women, one out of four made statements as to previous traumata. I should hardly have thought so many would have done so, for, supposing we put one half of them out of count at once as imaginary it would leave one case in eight in which there was not improbably some truth in the patient's statement. After the way in which the vulgar but rooted belief in the infectiousness of phthisis of the Italian peasant has, in the light of modern discovery, triumphed over the contemptuous disbelief of the whole world of medicine, I am not disposed to abandon all belief in the statements of women whom we will even admit to be anxious to find a cause for their malady. Constant repetition from different sources strengthens even a weak tale, provided the evidence be steadily in the same direction. I have investigated these stories too often not to feel that, stripped of all exaggeration, there is a distinct element of truth in them. Remember, $I$ do not make any attempt to assert that cancers of traumatic origin are at all frequent, but I believe in the possibility, and, indeed, in the strong probability, of their occurrence. I cannot see anything irreconcilable with our pathological knowledge in the idea of a blow leaving behind it a certain limited area of chronic inflammation in which the gland epithelium should begin to grow and then burst its bounds, just as I am certain it does in chronic mastitis. Dr. Boswell Park says: "The supposed intimate relation which injury bears to cancer is of no more importance than that upon which the clinicians, and even the pathulogists, used to place so much stress in tuberculosis. There are still those who claim that the predisposing cause of most tuberculous joint diseases is previous injury of some character and there are still those who look for a similar mechanical cause of cancer in virtually every case." I am not one of those who look for a mechanical cause of cancer in virtually every case, but I venture to say that there is no practising surgeon in this country who has much to do with joint disease who does not recognise the immense importance of wrenches, blows, and sprains in the production of the early inflammatory changes in and about joints which ultimately end in what is known as articular tuberculous disease. I was educated in exactly the opposite view-viz., that the tales which mothers told about injuries to their childrens's joints were all nonsense, and I was forced out of this belief by the irresistible arguments of experience.

One feels the more inclined to this view from the knowledge that acute traumatic malignancy is a well-recognised disease. Scattered throughout the medical journals are so many cases of its occurrence that no possible doubt can be entertained about its existence. In the British Medical Journal for 1882 are two short but very interesting papers on the subject by Mr. Barwell and Mr. Harrison Cripps, also a third by my friend Mr. Pazey of Liverpool detailing in a most interesting manner the history of a man who was struck over the sternum and in whom there was developed at the spot a sarcoma. It is true that, in all the cases which I have read about, sarcomata and not carcinomata supervened, and therefore the disease is rightly named "acute." But if injury will, so to speak, on the spot start into existence the swift-growing tumour of the connective tissue, why should it not at a longer interval give rise to the slowgrowing tumour of glandular lining epithelium ?

\section{THE SANITARY CONDITION OF IRISH NATIONAL SCHOOLS. ${ }^{1}$}

BY ANTONY ROCHE, M.R.C.P. IREL.,

PROFESSOR OF MEDICAL JURISPRUDENCE AND PUBLIC HEALTH, CATHOLIC UNIVERSITY MEDIGAL SCHOOL; RXAMINRR, ROYAL UNIVERSITY; FELLOW OF THE SANITARY INSTITUTF.

Tear the health of the individual and the community depends largely on their surroundings being sanitary is now universally admitted. That this rule is specially applicable to the young is acknowledged by all sanitarians, and that therefore their schools, wherein they spend so many hours, should meet all the requirements of modern sanitation will hardly be contested by anyone devoting any consideration to the subject. The growing and undeveloped structures of children, their close contact in schools for a number of hours, their less power of resistance to cold and other depressing influences, all render them remarkably susceptible to the causes and spread of disease. An inquiry, therefore, into the sanitary conditions of our national schools is not alone interesting but of great practical importance. According to the last official report there are no less than 8651 of these schools in Ireland and on their rolls 808,467 students. I have for some years been making personal observations and inquiries into the sanitation of these schools ; as, however, my sphere of observation has not extended over many parts of Ireland I will rely rather on the evidence of the inspectors of these schools and on official returns. These inspectors have had ample and extended opportunities of observation, they cannot be expected to be prejudiced against the system of which they form a part, and therefore when they speak so plainly of the insanitary condition of many of these schools their opinion may be trusted as impartial. I will now read some extracts from the reports taken from the last available report of the Commissioners of National Education.

Mr. A. Purser, head inspector, North Dublin Group of Districts, reports, Jan. 25th, 1898: "In my last report I referred to the necessity of requiring that schoolhouses should be suitable, kept in proper repair, and adequately warmed in cold and wet weather, and I again express as my opinion that 'the Commissioners should not tolerate the existence of national schools without offices unless under very exceptional circumstances, and should refuse salary for winter months if adequate fires for heating the schoolroom are not provided. It is not an extravagant supposition that a large part of the sickness among the children of the country is brought on by badly ventilated schoolhouses, combined with want of due warmth in wet and cold weather.' It is downright cruelty to have a schoolroom for the poorly clad children so cold that an inspector, even with a heavy overcoat on, feels chilled in hands and feet. But the providing of offices is not enough; they must be kept in a sanitary, clean, and decent state; and any serious neglect of this matter should be visited with heavy punishment where the fault does not lie with defective construction of these buildings. 'No credit is given, by the present system of paying teachers, for cleanliness, neatness, or ornamentation for house and premises ; none for regard to the health and comfort of the pupils; none for the educative example of decency and order, so these are naturally neglected in a greater or less degree.' A considerable number of recently built vested schools that $I$ have visited are very unsatisfactory structures, faulty in plan, unsound in construction, and, as a result, rapidly falling into bad repair. Within the last month I visited a pair of schools in the county Wexford, which had not been occupied a single week, built at the public expense by a grant of two-thirds of the nominal cost. It is probably no uncharitable supposition that these 'two-thirds' given by the Commissioners covered the whole cost of the building. The roof was not stannch; fittings, such as the boot-scrapers at the doors, had already given way; the woodwork was rough and unplaned and hence the varnishing will be of little avail in keeping it clean; it was also so fresh that the joints were everywhere opening; at the corners of the rooms where the ventilation tubes are placed one could see daylight through the wall and the

I A paper rear hefore the Statistical and Social Inquiry Society of Ireland on Feb. 20 th, 1900. 
teachers were obliged to fill up the chinks with paper. This is certainly very far from satisfactory and coupled with the after-neglect which is common in conntry places in regard to school buildings calls for the application of some check. It is very unadvisable to allow the applicant to be the contractor for building the house for which he has received a grant. For the above defect the teachers are, of course, in no way responsible. But in many cases they do not pay as much regard to cleanliness, neatness, and order as is desirabledefects which, partly owing to this neglect and bad example, are only too painfully observable in the children as well as in the schoolrooms. With regard to the schoolhouses, I would suggest that the ceilings should be flat; that where the services of one or more assistants are likely to be available a class-room should be built for each, not the little cell that usually is provided, but a room nearly as large as the main room and able to contain the assistant's whole division."

Mr. Sullivan, LL.B., head inspector, Galway Group of Districts, reports, Feb. 10th, 1898: "As I have said, the attendance in most schools is comparatively good in winter. But this is only when the winter is mild. A very large proportion of the children of this province is poorly fed and very poorly clad. It is painful to see-as an inspector cannot fail to see-little groups of bare-footed boys and girls, miserably clad, trying to make their way on a winter's morning to the neighbouring school. In such cases one hopes that the schoolroom, when reached, may make these poor children warm and comfortable. Unfortunately, this is not the case. My experience -and it is extensive-is that the schoolroom which awaits most children after their walk over bleak roads or paths is a cold, cheerless apartment. Some sods, of turf have been placed on the hearth and lighted, but as yet they give no heat, nothing but a mass of smoke. One day last January-and this day and the school may be taken as typical of many others - I was examining in such a cheerless room as that which I have above described. As the children came in they sat, quiet, melancholy, and miserable-looking, at the desks. I was glad to keep on my overcoat and I also had the advantage of moving about. The sods of turf-there were not many-though ' lighted' about 10 o'clock, smouldered away, but showed none of the usual appearance of a fire-- no blaze, no heat-nntil 11.30. Even then the fire added little or nothing to the heat of the room, but owing to the presence of the children the room began to get moderately warm."

Mr. F. Fardley, head inspector, Londonderry Group of Districts, reports, February, 1898: “A great mistake was made in the erection of many of these houses: they were built too small. A floor space of eight square feet per pupil was quite inadequate, seeing that out of that area had to be deducted the spaces for doors unwisely opening inwards; for the teacher's rostrum, an antiquated encumbrance; for a demonstration board, which was unsightly and almost useless; and for a free space round the fireplaces, so that schools built according to scale for the accommodation, say, of 75 pupils, were helplessly overcrowded when that number attended. A glaring defect in most of the schools is the condition of the out-offices. In the country the schools would be better off without them as they are kept-offensive alike both to health and to decency."

Mr. Alexander, head inspector, Cork Group of Districts, reports, Jan. 27th, 1898: "Teachers are required by rules of the board-(1) to promote, both by precept and example, cleanliness, neatness, and decency ; (2) to satisfy themselves by personal inspection every morning that the children have had their hands and faces washed, their hair combed, and clothes cleaned, and where necessary mended; (3) to have the school apartments swept and dusted every evening and whitewashed at least once a year; (4) to take every care to promote the health and comfort of the pupils; and (5) to impress upon the minds of their pupils the great rule of regularity and order-a time and place for everything, and everything in its proper time and place. I had to complain in my last report that so far as my observation extended these rules appeared to be very imperfectly observed. The experience gained during the past year does not enable me to qualify this statement-quite the contrary. Instances of culpable neglect of these important regulations have too frequently come under my notice. I visited the three schools in a large village not long ago at 10.15 in the morning. The weather was cold and wet. I found the teacher of the boys' school walking about doing nothing, while two boys were sweeping the floor and a third was endeavouring to light the fire. In the adjoining infants' school I found a few children huddling together in a cold, cheerless room. The mistress explained that she had been obliged to go in search of materials for a fire, hence the delay in commencing business. On a pouring wet morning in September last I visited the male and female schools in a certain locality at 930 and found neither of the teachers in attendance. The boys had to remain without shelter till 10 o'clock, and the girls till 1015 o'clock, at which hours, respectively, the principals of the two schools arrived. In the case of another school the inspector of the district had to draw attention in $\mathbf{1 8 9 5}$ to the filthy condition of the offices, and his successor found it necessary to do the same in 1896. I visited the school towards the end of 1897 and found matters worse than ever in that respect."

Mr. J. Moran, head inspector, Belfast Group of Schools, reports, Jan. 24th, 1898: "I have little to add to the few remarks on schoolhouses in my report of last year. Several are altogether unsuitable and some have no out-offices attached. I regret to find that some of the inspectors recommend, in special cases, a grant to a school conducted in an unsuitable house. Of course, we are told, this is only a temporary arrangement. A new school is to be built forthwith, or as soon as funds are available, but so soon as the grant is obtained no further steps are taken."

Mr. W. J. Browne, M.A., district inspector, Londonderry, reports, Jan. 29th, 1898 : "In many instances the out-offices are damp and badly ventilated, with earthen foors."

Mr. H. Cox, district inspector, Coleraine, reports, Jan. 31st, 1898: "Ventilation, too, is another point that does not receive sufficient attention. It must be within the knowledge of all the members of the inspection staff that very often, instead of all the windows of a schoolroom freely admitting of being opened for ventilation, they are nailed so as to prevent this. I have of ten gone into a school where, after remaining only a few minutes, I have had a bad headache from having been obliged to breathe the foul, unventilated air. Is it a matter for surprise that in such schools the pupils become languid, inattentive, unreceptive; and that the teacher finds himself at the end of the day completely exhausted - to become eventually anæmic or worse?"

Mr. J. Chambers, B.A., district inspector, Strabane, reports January, 1898: "The remaining schoolhouses are as a rule substantially built, but the lighting and the sanitary arrangements of several of them are defective."

Mr. J. P. Dalton, M.A., district inspector, Belfast, reports, Jan. 31st, 1898: "And 21 schools have been enlarged. The evil of overcrowding is yet far from being abolished. The district, moreover, is still disfigured by the existence of some balf a dozen schools of such defective "construction and illchosen situations that they would bring reproach upon any district, while they form an exceptionally discreditable contrast to the great majority of the fine school buildings which are to be seen in every part of the city."

Mr. J. M'Neill, B.A., another district inspector, Jan. 12th 1898, reports: "With regard to school buildings the general state of things is only fairly satisfactory. Schools vested in the Commissioners are of course well looked after and those vested in the trustees are also kept in fair repair. But several of the non-vested class are unsuited for schoolhouses. of late years one or two of the worst have been replaced by proper buildings and negotiations are going on with respect to several others. About a dozen still remain that are only a degree better than ordinary cabins. Repairs to non-vested schools have sometimes to be made by the teacher; sometimes a concert is held and funds are raised. These extensions and repairs should if practicable meet with more encouragement from the department."

Mr. J. Ross, M.A., district inspector, Newry, January, 1898, reports: "In eight instances, seven being mixed schools, no sanitary provision exists. In a few instances the windows of the schools are furnished with diamond panes and the lighting is in consequence unsatisfactory."

Mr. W. J. McClintock, M A district inspector, Cavan, reports January, 1898: "A considerable number of instances of unsuitable accommodation, however, still remain, and there are five cases in which the houses are extremely defective and the pupils suffer from insufficient light and from imperfect ventilation. The offices are kept fairly clean and the rooms are, as a rule, limewashed once a year, but the teachers are often remiss in their duty as to dusting-the walls and tablets afford indisputable evidence on this point. The want of an abundant supply of fuel is much felt in many localities, where no provision is made for a fire except the few turf which the pupils bring with them from day to 
day. This circumstance, combined with the excessive moisture of the climate, makes the walls damp and renders many of the houses incapable of affording a high degree of comfort in inclement weather. In numerous instances the premises are very small or non-existent and the playground is the adjacent road or lane. This want of sufficient space outside has sometimes necessitated the erection of offices against the wall of the house - an arrangement which must be highly objectionable from a sanitary point of view."

Mr. D. F. Fitzgerald, B.A., district inspector, Ballinamore, reports January, 1898: “These will still leave 17 houses which cannot be decided otherwise than bad. They are, for the most part, wretched hovels, thatched, unceiled, with rugged clay floors, imperfectly lighted, and still more imperfectly rentilated, and provided with neither offices nor playground; they are poorly furnished, afford inadequate accommodation, and offer no facilities for teaching."

Mr. J. P. D. Lynam, M.A., district inspector, Templemore, reports January, 1898: "With some notable exceptions the school buildings and furniture in this district are very fairly adapted to their purpose. But there is almost universally an absence of taste, and even of cleanliness, which is much to be regretted. Even in some of the modern vested schools the walls are bare and grimy, the roofs cobwebby, the windows dirty, and the playground more like a pen for domestic animals than a place of recreation for young people. Bareness and squalor, unrelieved by any touch of care or adornment, are the prevailing features. The homes of the Irish peasantry are not remarkable for order and cleanliness, and at school they see little to improve them in this respect. A very small expenditure with a certain amount of trouble would be sufficient to make the schools neat and tasteful in appearance. There seems to be no way of remedying the present state of things, except by making the teacher's income depend to some extent on the appearance of his school."

Mr. J. F. Hogan, district inspector, Ennis, reports January, 1898: "In four of the small towns in this district new schools are needed. In the first case there is no chance of securing a site; the landlord will give nothing except at an exorbitant figure and the prospect of heavy costs deters the manager from availing of the compulsory powers for acquiring that site. In two others the site can be got now ; local aid is forthcoming, but building grants are not available, and when they are the manager may not be able to secure the plot of ground. In the fourth case the buildings are not very bad but old-fashioned and falling out of repair; here, again, no grants are available. In these three cases, I fear, old unsuitable houses will have to be put up with for years to come. For schools classified as 'bad' in the annual returns of each district some steps should be taken-that is, when building grants are to be got-to support managers in securing local aid and to rouse the parents of the pupils from their a pathy. Each inspector should be asked to furnish a list of these schools. These lists should be placed in the hands of an officer of the Board of Works competent to give a professional opinion on the state of building repair and sanitary accommodation. He would then visit each school and furnish a short report. These schools should then be placed in a special schedule published each year. No new appointments should be made in them, no monitors recommended, and according as vacancies occur they should not be filled in."

Mr. J. A. Coyne, B.A., district inspector, Tralee, reports January, 1898 : "There are 13 schools without out-offices."

Mr. Louis Daly, M.A., district inspector, Mallow, reports March, 1898: "About two-thirds of the schools here are fairly comfortable and well warmed. Ventilation, however, during the school day does not receive due attention and I have very frequently to complain of neglect of this important matter. The practical rule on this subject could generally be much more effectively observed.'

Now let us turn to another section of the official report wherein the schools are classified :-1. As regards the cleanliness of the out-offices I find that out of 8542 schools the outoffices are described as middling or bad as regards cleanliness in no less than 2068, and that in 823 there are no outoffices at all-a state of things both immoral and insanitary 2. As regards building repairs I find that 2411 schools are reported as middling or bad. 3. Furniture and apparatus are reported as middling or bad in 2590 schools. 4. Premises and playground are reported as middling or bad in 2344 schools. There is no playground in 1577. 5. Space accommodation is middling or bad in no less than
1713 schools. These are important and certainly not satisfactory returns. I find also that out of 808,467 students on the rolls only 211 passed in the subject of hygiene. Moreover, in only one of the five training colleges is this subject taught, and of 843 internal students in these colleges training for teachers actually only three passed in it.

I think that I have shown conclusively that sanitary laws are neglected and outraged in many of the national schools in Ireland. The importance of this to the children, and to the community of which they constitute so important a part as the coming generation of our workers, is self-evident. I will not apportion the blame of the existing state of things. How far the Government, the Board of National Education, the managers, and perhaps in some respects the teachers, are each responsible, or conjointly so, I will not, at least on the present occasion, enter into; but this I do unhesitatingly say, that no shifting of responsibility can or should be allowed to hinder or delay reform. I hope the Press will direct the attention of the people and of our members of Parliament to the facts which I have laid before you, and that practical and immediate efforts will thus be made to do justice to our poor people and their children.

I wish to make here two acknowledgments. First, that the greatest credit should be given to the head and district inspectors for their repeated and emphatic condemnation of the sanitary abuses that come so constantly under their notice. It is too frequently the custom for officials connected with any system to overlook or hide the defects of that system. Their rising above this common fault shows that they are worthy, not alone of the confidence of their Board, but, of much more importance, of the public. Secondly, I fully allow and appreciate the improvements that have been made in many of the schools in sanitary matters, but $I$ consider that this improvement in some schools is only an argnment of what could and should be done in others. It might be interesting were I to give a summary of what has been done in school sanitation in America and in many continental countries, but already this paper has, I am afraid, exhausted your patience, so I must reserve it for some future occasion.

I will conclude by giving some suggestions towards reform that have occurred to me during my study of this question. I do not lay them before you as a complete scheme, but rather as hints towards the drawing of such. First, it is evident that the schools directly under the Board are better kept and inspected than those under their partial control. Secondly, the plans and inspection of new schools seem, in some cases at least, to have been defective. This is inexcusable and those responsible ought to be made answerable and care taken in the future that both plans and inspection are above question; at least, the public have a right to expect that the new schools will not perpetuate recognised sanitary defects. Thirdly, the keeping of the new structures in repair seems frequently, according to the reports, to be neglected. Fourthly, in the winter the schoolrooms should be warmed. If no fund at present exists for this purpose an application to Parliament should be made for a grant. Fifthly a special sanitary report should be made and published of every national school by competent authorities-and where the sanitary defects are removeable they should be; when not, a new building should be insisted on. The cubic space for each child, the ventilation, the heating, the sanitary accommodation which should be available in every school, the state of the buildings and the dryness of the walls and roof, and the ground for recreation should be specially noted. It may be objected that there are no funds to meet this expenditure. Then apply to Parliament. No better use could be made of the public money. Sixthly, the instruction of our teachers in hygiene. It is quite evident from many of the reports that they do not appreciate at present the importance of this science. I have already shown the few who qualify in it; the subject should be made compulsory for all teachers, so that they may, in their turn, impart at least some knowledge to their pupils. Seventhly, the National Board ought to have a competent adviser to whom they might refer the many health questions that so frequently arise. The London School Board have such a referee and his use is shown by the valuable report published yearly by the Board giving the immense amount of sanitary work done. Many of the school boards throughout England have also appointed a medical sanitary adviser. Eighthly, the printing and circulation amongst the children of simple instructions in the elements of sanitation and the best methods of preserving their health and avoiding disease. 
If such suggestions were adopted $I$ have no doubt that the health of our children would be greatly improved and that the schools would be object-lessons in sanitation and cleanliness, which in many cases they certainly are not at the present time. Dublin.

\section{A CASE OF RUPTURE OF THE BRACHIAL PLEXUS.}

BY PURVES STEWART, M.A., M.D.EDIN., M.R.C.P.LoND., ASSISTANT PHYSICIAN TO THE WESTMINSTER HOSPITAL, AND

MAYO COLLIER, M.S. LOND., F.R.C.S. ENG., SURGEON TO THE NORTH-WEST LONDON HOSPITAL.

CASES of rupture of the brachial plexus are somewhat uncommon and the following instance is of value, not only because of the remarkable extent of injury to the plexus, but also because it exemplifies several interesting physiological points.

A man, aged 33 years, was admitted into the North-West London Hospital in the early morning of Sept. 6th, 1899, in a state of semi-consciousness. He had been found by the police lying on the road, apparently having fallen from a machine road-brush that was in the vicinity. No one witnessed the fall and it was only elicited some days afterwards that he had been in charge of the machine. On admission the patient was only partially conscious; he was noisy, struggling, and difficult to manage, but he did not show any evidence of having been drinking. There was a wound of the left side of the head in the parietal region which apparently involved the scalp only. No fracture of the skull could be made out. The house surgeon did not detect any paralysis of the face or limbs at the time, though it is certain that the right upper extremity must have been paralysed. The right pupil was, however, observed to be smaller than the left. There was a contusion extending from the side of the neck on the right side over the right shoulder to the front of the axilla. There was no other evidence of injury. The semi-consciousness and restlessness soon passed into a quiet coma. He was watched for signs of increasing compression of the brain, but the coma gradually passed off and at the end of a week the patient was quite conscious. He then stated that he had not had anything to drink for many hours before the accident. He remembered pulling up at a coffee-stall and then starting" off again, but after that he remembered nothing. The patient's wife stated that he was subject to epileptic fits at long intervals. His right arm and hand remained severely paralysed, no improvement whatever ensuing.

On examination on Nov. 13th, 1899 (ten weeks after the injury), the patient was found to be a healthy-looking man of fair intelligence. His right upper extremity was obviously totally paralysed. He had a bald patch over the right parietal eminence, the result of an old injury which he had received eight years before, possibly during an epileptic fit. The optic discs and all the cranial nerves appeared to be normal and there was no motor or sensory abnormality of the face, trunk, or limbs, with the exception of that in the right upper extremity. All external ocular movements could be executed to their full extent. There were, however, slight horizontal nystagmoid jerks on turning the eyes to the left or upwards, but none on looking to the right or downwards. The reflexes in the lower limbs, both superficial and deep, were normal. No abnormality could be detected at the root of the neck on either side. There were no swelling and no tenderness on palpation, but passive abduction of the right shoulder was painful.

With regard to the cervical sympathetic the pupils were unequal, the right (three millimetres) being slightly smaller than the left (four millimetres) (see Fig. 1). They contracted normally to light and during convergence. Both pupils dilated when shaded but the dilatation was distinctly better marked, both in degree and in briskness, on the left side than on the right. On pinching the neck the cilio-spinal reflex was absent on the right side but normal on the left. The right eye was a little sunken and the right palpebral fissure was distinctly narrower than the left (see Figs. I and 2). On dropping a few minims of solution of cocaine, however, into the right pupil it dilated well and the palpebral aperture widened.

Examination with regard to the sensory functions revealed that there was absolute anæsthesia to touch, pain, and temperature over most of the right upper extremity, the anæesthesia including the entire hand and forearm and extending far up the upper arm. Two strips of normally sensitive skin survived, however, one on the front of the upper arm (see Fig. 2) over the upper part of the biceps muscle, the other on the inner and back part of the upper arm over the triceps. A narrow "tongue" of anæsthesia ran upwards along the axillary side of the arm, separating those two areas (see Figs. 3 and 4). There was complete loss of sense of position on passive movement at the right elbow, the wrist, and the fingers. The sense of position was normal at the right shoulder and at all the otber joints of the body. When the patient moved his right arm passively by means of his left hand he felt as if he had a "phantom right hand" hanging constantly by his side with its palm facing backwards.

As to the motor functions, the movements of the scapula were apparently normal although the right trapezius seemed a little weaker than that on the left side. The patient could brace back both scapulæe equally well, bringing the whole vertebral border of each scapula towards the middle line-i.e., the rhomboid muscles were normal. The inferior angle of the right scapula at rest was a little more prominent than that on the left side (Fig. 3), but there was no "winging" of the scapula on pushing forwards against resistance when the arm was held horizontally forwards (i.e., the serratus magnus was not paralysed). The right shoulder was distinctly flattened from wasting of the deltoid, the pectoral muscle was wasted, and the supra-spinous fossa was hollowed out (see Figs. 2 and 3). Immediately below the right acromion process there was a gap into which the finger could be put, which was due to downward displacement of the humerus. This gap disappeared temporarily when the elbow was passively supported, but it reappeared at once on withdrawing the support. The distance from the acromion process to the external condyle of the humerus when the limb hung unsupported was two inches more on the injured side than in the sound limb (see Figs. 2 and 3 ). There was absolute flaccid paralysis of the right shoulder, elbow, wrist, and fingers. The muscles were soft and flabby, and the limb dangled loose in a flail-like manner. The latissimus dorsi was paralysed on the affected side and, unlike its fellow, could not be felt to contract when the patient coughed. The supinator and triceps jerks were absent in the paralysed arm, whilst on the left side they were both brisk.

The state of the electrical reactions, \&c., was as follows. There was no reaction to the strongest faradaic shocks in the right pectoral, the deltoid, the biceps, the triceps, or any muscle of the upper arm, the forearm, or the hand. The right trapezius reacted normally. The right deltoid, the biceps, and the extensor muscles of the fingers being selected for testing with the galvanic current, they showed marked diminution of excitability with sluggish contraction, ACO being $>$ KCO. The skin of the right hand was red and congested and was much colder than that on the sound side. There were no cracks, ulcers, or other trophic changes in the skin or nails.

There are several points of considerable interest in this case. With regard to diagnosis, the fact of the patient being admitted in an unconscious state with a bruise on the left side of his head and with paralysis of his right arm suggested to some observers that the paralysis was due to a cerebral injury. The profound anæsthesia of the limb, however, was against such a theory ; moreover, the paralysis was of a flaccid type, unlike the rigidity of a cerebral paralysis. Subsequent examination showed the presence of marked muscular atrophy and of the reactions of degeneration. Such a combination of anæsthesia, motor paralysis, and muscular atrophy pointed at once to an extensive lesion of the peripheral nerves supplying the upper limb.

Eight weeks after his accident the patient had another epileptic fit in which all the limbs were convulsed, with the exception of the paralysed arm. This is of interest when it is contrasted with what would have been the case had the paralysis been due to an injury in the region of the motor centre for the right arm, in which case the convulsion would probably have affected the paralysed arm and might even have commenced there. The probability, therefore, is that 